\title{
Recurrent Milk Aspiration Produces Changes in Airway Mechanics, Lung Eosinophilia, and Goblet Cell Hyperplasia in a Murine Model
}

\author{
IBRAHIM A. JANAHI, OKAN ELIDEMIR, FELIX R. SHARDONOFSKY, \\ MUTASIM N. ABU-HASSAN, LELAND L. FAN, GARY L. LARSEN, \\ MICHAEL R. BLACKBURN, AND GIUSEPPE N. COLASURDO
}

\author{
Department of Pediatrics, Section of Pediatric Pulmonology, Baylor College of Medicine, Houston, Texas \\ 77030, U.S.A. [I.A.J., F.R.S., M.N.A., L.L.F.]; Department of Pediatrics, Division of Pulmonary Medicine, \\ National Jewish Medical and Research Center, Denver, Colorado 80206, U.S.A. [G.L.L.]; and \\ Departments of Pediatrics [G.N.C., O.E.] and Biochemistry [M.R.B.], University of Texas-Houston \\ Medical School, Houston, Texas 77030, U.S.A.
}

\section{ABSTRACT}

\begin{abstract}
Recurrent aspiration of milk into the respiratory tract has been implicated in the pathogenesis of a variety of inflammatory lung disorders including asthma. However, the lack of animal models of aspiration-induced lung injury has limited our knowledge of the pathophysiological characteristics of this disorder. This study was designed to evaluate the effects of recurrent milk aspiration on airway mechanics and lung cells in a murine model. Under light anesthesia, BALB/c mice received daily intranasal instillations of whole cow's milk $(\mathrm{n}=7)$ or sterile physiologic saline (n = 9) for $10 \mathrm{~d}$. Respiratory system resistance (Rrs) and dynamic elastance (Edyn,rs) were measured in anesthetized, tracheotomized, paralyzed and mechanically ventilated mice $24 \mathrm{~h}$ after the last aspiration of milk. Rrs and Edyn,rs were derived from transrespiratory and plethysmographic pressure signals. In addition, airway responses to increasing concentrations of i.v. methacholine (Mch) were determined. Airway responses were measured in terms of $\mathrm{PD}_{100}$ (dose of Mch causing $100 \%$ increase from baseline Rrs) and Rrs, max (\% increase from baseline at the maximal plateau response) and expressed as \% control (mean \pm $\mathrm{SE}$ ). We found recurrent milk aspiration did not affect Edyn and baseline Rrs values. However, airway responses to Mch were
\end{abstract}

increased after milk aspiration when compared with control mice. These changes in airway mechanics were associated with an increased percentage of lymphocytes and eosinophils in the bronchoalveolar lavage, mucus production, and lung inflammation. Our findings suggest that recurrent milk aspiration leads to alterations in airway function, lung eosinophilia, and goblet cell hyperplasia in a murine model. (Pediatr Res 48: 776-781, 2000)
Abbreviation
Rrs, respiratory system resistance
Mch, methacholine from baseline response
GER, gastroesophageal reflux
ASM, airway smooth muscle
BAL, bronchoalveolar lavage
AHR, airway hyperresponsiveness
NEP, neutral endopeptidase

Edyn,rs, dynamic elastance of the respiratory system

PD $_{\mathbf{1 0 0}}$, dose of methacholine causing $100 \%$ increase of Rrs

Rrs,max, \% increase from baseline at the maximal plateau
Recurrent aspiration of foreign material into the respiratory tract is a common problem in children and patients with predisposing anatomic and functional disorders such as tracheoesophageal fistula, GER, and neuromuscular disorders (1-3). As a result, it has been implicated in the etiology of a variety of pulmonary disorders (1-3). Clinically, children who

Presented, in part, at the International ATS/ALA Conference, San Diego, California, April 24, 1999

Received January 26, 2000; accepted July 26, 2000.

Address correspondence to Giuseppe N. Colasurdo, M.D., Department of Pediatrics, UT-Houston Medical School, 6431 Fannin, MSB 3.146A, Houston, Texas 77030, U.S.A.

This work was supported, in part, by grants HL-03196 and HL-03784 from the National Institutes of Health. aspirate may present with pneumonia, recurrent wheezing, unexplained cough, interstitial lung disease, and even apnea (1-3). Furthermore, an association between aspiration of milk and exacerbation and/or development of asthma has been suggested (4). Children with asthma commonly have GER, but it is not always clear if GER causes, exacerbates, or is the result of the asthma itself (4). In this respect, the interpretation of clinical studies represents a clinical challenge in terms of establishing a cause-effect relationship between GER, aspiration, and pulmonary sequelae (4-7).

An association between milk aspiration and the development of airway dysfunction has been suggested by clinical and 
laboratory studies in recent years (4-8). Although the clinical relevance of recurrent aspiration is widely recognized, the mechanisms by which aspiration induces lung injury are poorly understood. In this respect, limited information is available on the role played by immune cells in the development of altered airway function seen in response to milk aspiration. Work conducted in our laboratory has recently investigated the effects of repeated milk aspiration on the autonomic regulation of rabbit airways in vitro (8). These studies showed recurrent aspiration of milk produces significant alterations of the contractile and relaxant responses of ASM (8). Of interest, these changes of airway function appear to reproduce alterations of neural control mechanisms seen in other mammalian models of lung inflammation $(9-11)$.

Our laboratory has recently developed a murine model of milk aspiration (12). Using immunocytochemical staining of milk proteins within alveolar macrophages, we described a novel diagnostic method for pulmonary aspiration (12). To further investigate the mechanisms by which aspiration may lead to airway dysfunction, we performed measurements of respiratory system mechanics in vivo. Furthermore, we evaluated the presence of inflammatory cells in the BAL fluid and lung tissue in our mouse model.

\section{METHODS}

Experimental animals. Female BALB/c mice ( 8 wk of age), obtained from Harlan Sprague Dawley, Inc. (Indianapolis, IN), were used for all studies. All the procedures used in this study were approved by the Animal Care and Use Committee of the University of Texas Health Science Center and Baylor College of Medicine at Houston and conformed to National Institutes of Health guidelines.

Production of milk aspiration. Cow's milk was used as the aspiration medium. After sedation with ketamine and xylazine, $50 \mu \mathrm{L}$ of milk was placed into the nose of quietly breathing mice while the mouth was closed. This technique, a modification of methods previously described by our laboratory (8-11), allows for aspiration of milk or saline into the lungs with strong respiratory effort as evidenced by the coughing produced with inoculation of either material. The procedure did not lead to awakening of the mice, and the coughing resolved within $30-60 \mathrm{~s}$ after completion of the nasal injection of milk or saline. This protocol was used for single and repeated aspiration. The latter was accomplished by instilling $50 \mu \mathrm{L}$ of milk daily for $10 \mathrm{~d}$. Control animals received normal saline in an identical manner and schedule. In vivo experiments of lung mechanics, BAL fluid cell analysis, and histopathological studies were performed $24 \mathrm{~h}$ after the last aspiration event as described below.

Measurement of respiratory system mechanics. In vivo studies of respiratory mechanics were performed in anesthetized, tracheotomized, paralyzed, and mechanically ventilated animals, as previously described (13). After a tracheal cannula was inserted and secured, animals were placed inside a $0.37-\mathrm{L}$ Plexiglas pressure-sensitive body plethysmograph. The cannula was connected to a mouse ventilator (Harvard Apparatus 687 ) that produced quasi-sinusoidal inspiratory flow and al- lowed passive, quasi-exponential expiratory flow. The ventilator was set to provide supplemental oxygen, tidal volume of $13.0 \pm 1.0 \mathrm{~mL} / \mathrm{kg}$ (mean $\pm \mathrm{SE}$ ), respiratory rate of $120 / \mathrm{min}$, and positive end expiratory pressure of $5 \mathrm{~cm} \mathrm{H}_{2} \mathrm{O}$. Plethysmograph (Pbox) and tracheal pressure signals were amplified, low-pass filtered at $10 \mathrm{~Hz}$ (8-pole Bessel 902LPF, Frequency Devices, Haverhill, MA, U.S.A.), and sampled at $40 \mathrm{~Hz}$ with an analog-to-digital converter (DT 2801-A, Data Translation, Marlborough, MA, U.S.A.). Flow was obtained by digitally differentiating the volume signal. Both Rrs and dynamic elastance Edyn,rs were estimated as a function of time off-line by applying a recursive least-square algorithm to the equation of motion of the single compartment linear model of the respiratory system (14). Rrs and Edyn,rs were corrected for equipment resistance and elastance, respectively, and measured at baseline and during incremental doses of i.v. Mch. After completion of the in vivo respiratory mechanics studies, the step response of the plethysmograph was measured by rapidly injecting $0.3 \mathrm{~mL}$ of gas into the plethysmograph with the mouse paralyzed in situ (15). The first $10 \mathrm{~s}$ of Pbox after the injection were found to be well described by the sum of two decaying exponential functions, which accounted for the combined effects of a slow leak and the gradual conversion from adiabatic and isothermal conditions inside the plethysmograph after the sudden compression of gas. The parameters of the exponential were used to convert Pbox into the volume as described by Bates (16). Using our system, the values for Rrs and Edyn,rs obtained from the corrected volume are similar to those obtained using the uncorrected volume signal. This indicates that our pressure-sensitive body plethysmograph exhibits an adequate frequency response in the range of the experimental respiratory rate used in our studies. Indices of respiratory responses to Mch were expressed in terms of $\mathrm{PD}_{100}$ (dose of Mch causing 100\% increase in Rrs above baseline value) and Rrs,max (\%Rrs value at maximal plateau response). Results were measured as percentage of baseline values and expressed as mean $\pm \mathrm{SE}$.

Bronchoalveolar lavage fluid studies. Following studies of airway mechanics, animals underwent BAL with four aliquots of $0.5 \mathrm{~mL}$ of PBS, with approximately $90 \%$ recovery. Aspiration was confirmed by immunocytochemical staining of alveolar macrophages for beta-lactoglobulin, as recently described (12). Total cell count (cells $/ \mathrm{mL}$ ) was determined using a hemocytometer (mean $\pm \mathrm{SE}$ ). Cell differentials were calculated from slides prepared with modified Wright's stain and expressed as percentage of total BAL fluid cells.

Histopathological studies. After completion of the in vivo studies and BAL, mice were euthanized and the lungs removed and perfused with $10 \%$ buffered formalin. Lungs were then fixed overnight, embedded in paraffin, and then sectioned and stained with hematoxylin-eosin. Examination of lung histology was performed using light microscopy. Furthermore, PAS staining was performed to evaluate the presence of mucus production within the airway walls. The latter was accomplished by using Image-Pro ${ }^{\circledR}$ Plus analysis software (Media Cybernetics, Silver Spring, MD, U.S.A.). PAS-stained material was identified on digitized images, and the pixel intensities of each color channel were averaged. This was repeated for each 
image, and the values averaged to determine the area (M) and intensity (I) of PAS-stained material within the airway walls. In addition, the area (A) of the total epithelium including PAS-staining material was determined. Results were expressed by using a mucus index determined by the following equation: $\mathrm{M} \times \mathrm{I} / \mathrm{A}$. Final indices represented the mean $\pm \mathrm{SE}$ of eight images per lung including large and small bronchial airways.

Statistical analysis. All results were expressed as mean \pm $\mathrm{SE}$, where $\mathrm{n}$ equals the number of animals. Student's unpaired two-tailed $t$ test and two-way analysis of variance were used to determine the level of differences, where appropriate. A $p$ value of $<0.05$ was considered significant.

\section{RESULTS}

Studies of respiratory mechanics. After preliminary studies at various time points following single and repeated aspiration of milk, animals received daily inoculations of milk for $10 \mathrm{~d}$ as described above. In vivo studies of respiratory mechanics were performed $24 \mathrm{~h}$ after the last aspiration event. Recurrent milk aspiration did not affect baseline dynamic elastance (Edyn,rs) when compared with control animals: $53.1 \pm 3.2(\mathrm{n}=7)$ versus $46.7 \pm 6.2(\mathrm{n}=9) \mathrm{cm} \mathrm{H}_{2} \mathrm{O} \cdot \mathrm{mL}^{-1}$, respectively (Fig. 1). Baseline Rrs was greater after recurrent milk aspiration when compared with control mice: $0.76 \pm 0.1(\mathrm{n}=7)$ versus $0.55 \pm$ $0.05(\mathrm{n}=9) \mathrm{cm} \mathrm{H}_{2} \mathrm{O} \cdot \mathrm{mL}^{-1} \cdot \mathrm{s}$ (Fig. 2). However, the difference between these values did not reach statistical significance $(p=$ 0.061 ). The respiratory system responses to increasing concentrations of Mch were enhanced after milk aspiration as demonstrated by the Mch dose-response curve shown in Figure 3. Although $\mathrm{PD}_{100}$ values were not different between the two groups, the maximal response to Mch (Rrs,max) was increased by recurrent milk aspiration when compared with control animals: $1160 \pm 232.0(\mathrm{n}=7)$ versus $516 \pm 84.2(\mathrm{n}=9) \mathrm{cm}$ $\mathrm{H}_{2} \mathrm{O} \cdot \mathrm{mL}^{-1} \cdot \mathrm{s}$, respectively (Fig. 3) $(p=0.02)$.

Analysis of bronchoalveolar lavage fluid. To evaluate the effects of recurrent milk aspiration on the cellular constituents of BAL fluid, lung lavage was performed after completion of the in vivo studies of airway mechanics. The total number of

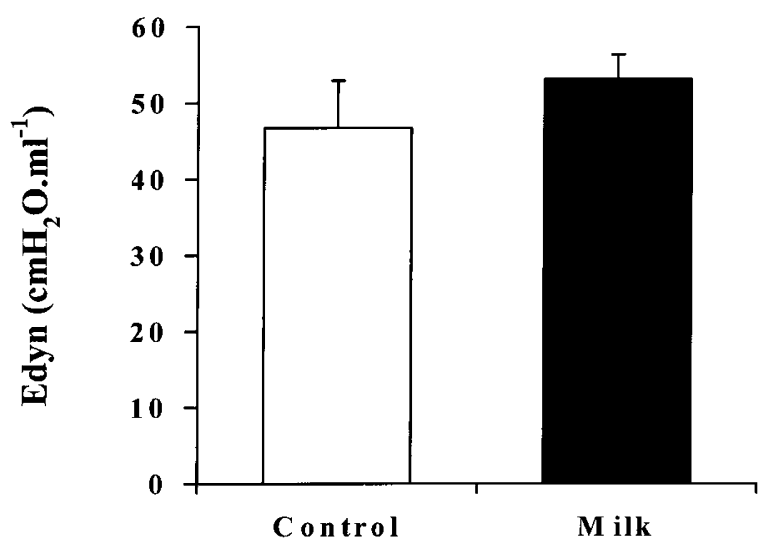

Figure 1. Effect of milk aspiration on baseline Edyn,rs in mice. Animals received daily intranasal instillations of cow's milk $(50 \mu \mathrm{L})$ for $10 \mathrm{~d}(\mathrm{n}=7)$. Control animals received normal saline in a similar manner $(n=9)$. Edyn,rs is expressed in terms of $\mathrm{cm} \mathrm{H}_{2} \mathrm{O} \cdot \mathrm{mL}^{-1}$ (mean $\pm \mathrm{SE}$ ). Aspiration of milk did not affect baseline dynamic elastance $(p>0.05)$.

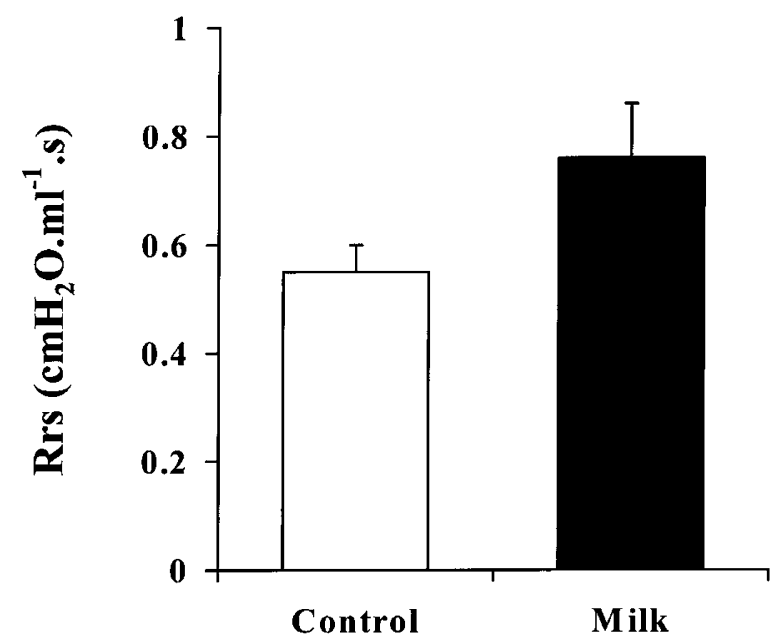

Figure 2. Effect of milk aspiration on baseline Rrs in mice. Animals received daily intranasal instillations of cow's milk $(50 \mu \mathrm{L})$ for $10 \mathrm{~d}(\mathrm{n}=7)$. Control animals received normal saline in a similar manner $(\mathrm{n}=9)$. Rrs is expressed in terms of $\mathrm{cm} \mathrm{H}_{2} \mathrm{O} \cdot \mathrm{mL}^{-1} \cdot \mathrm{s}$ (mean $\pm \mathrm{SE}$ ). Although baseline Rrs was increased after recurrent milk aspiration, it did not reach statistical significance when compared with control values $(p=0.061)$.

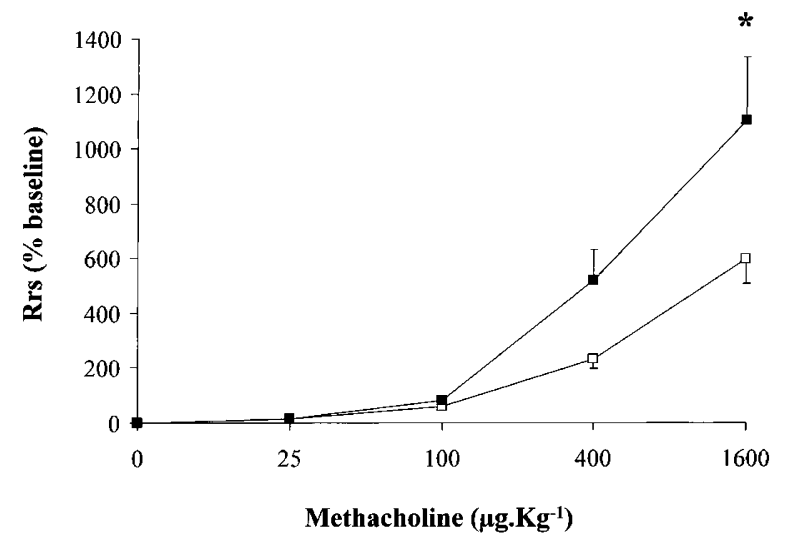

Figure 3. Effect of milk aspiration on airway responsiveness to Mch. Data were obtained as mean $\pm \mathrm{SE}$ and expressed as percentage of baseline Rrs after i.v. infusion of increasing doses of Mch $\left(25-1600 \mu \mathrm{g} \cdot \mathrm{kg}^{-1}\right)$. The maximal response to Mch (Rrs,max) was increased by recurrent milk aspiration when compared with control values $(* p=0.02)$.

cells recovered by BAL was significantly increased after $10 \mathrm{~d}$ of milk aspiration when compared with control mice: $28.4 \pm$ $4.1 \times 10^{4} / \mathrm{mL}$ and $15.1 \pm 3.2 \times 10^{4} / \mathrm{mL}$, respectively $(p=$ $0.003)$. After repeated milk aspiration, the differential cell counts obtained in BAL fluid revealed the following: $59.6 \pm$ $12.0 \%$ macrophages, $12.0 \pm 2.8 \%$ neutrophils, $12.4 \pm 2.1 \%$ lymphocytes, and $16.0 \pm 3.6 \%$ eosinophils (Fig. 4). The percentage of lymphocytes and eosinophils was significantly enhanced by aspiration of milk when compared with control mice $(p<0.05)$ (Fig. 4).

Histologic studies of lung tissue. The examination of lung morphology in mice exposed to repeated aspiration of milk was performed by light microscopy of histologic sections stained with hematoxylin and eosin. These studies were performed on tissues removed from mice after completion of the in vivo studies of respiratory mechanics. Furthermore, sections of lung tissue were also obtained from animals prepared only for 


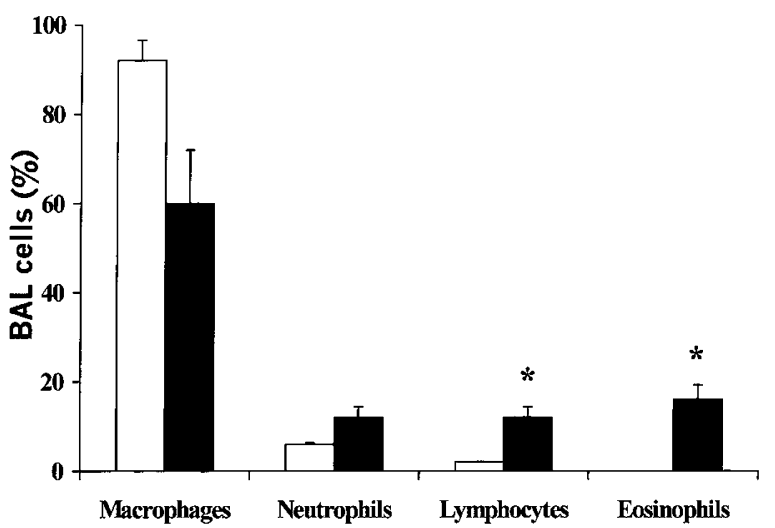

Figure 4. Effect of milk aspiration on bronchoalveolar lavage fluid cellularity. Animals received daily aspiration of milk for $10 \mathrm{~d}$. Control mice received normal saline in a similar manner. Results were expressed in terms of $\%$ total BAL fluid cells (mean $\pm \mathrm{SE}$ ). The percentage of lymphocytes and eosinophils was increased by aspiration of milk when compared with control animals $\left({ }^{*} p\right.$ $<0.05)$.

histologic studies. Representative sections of control and experimental animals are shown in Figure 5. Repeated milk aspiration produced significant inflammatory changes within lung tissues as demonstrated by a thickened airway epithelium and diffuse infiltration of mononuclear cells in the peribronchial and interstitial spaces (Fig. 5B). The area of higher magnification in Figure $5 B$ reveals the presence of eosinophils and mononuclear cells within areas of inflammation. Normal parenchymal architecture from a control animal is shown in Figure $5 \mathrm{~A}$. When evaluating the effects of milk aspiration on the airway epithelium, we found a significant thickening of the epithelial layer associated with marked goblet cell hyperplasia (Fig. 6B). The area of higher magnification depicts a distinct positive staining of goblet cells. Representative sections of airways obtained from control animals are shown in Figure 6A. As a result, the mucus index, obtained as described above, was significantly increased after milk aspiration when compared with control animals: $21.7 \pm 4.7$ and $0.3 \pm 0.2$, respectively (Fig. 7, $p<0.0001$ ).

\section{DISCUSSION}

Clinical and laboratory observations have repeatedly suggested an association between aspiration and pulmonary dis- orders (1-8). In children, repeated episodes of aspiration have been shown to produce a variety of lung disorders: pneumonia, bronchiectasis, chronic cough, interstitial lung diseases, recurrent wheezing, and apnea (1-7). As a result, significant loss of lung function and even respiratory failure may occur (2). In infants and young children, aspiration of milk is capable of inducing clinical symptoms of airway obstruction associated with other important features of chronic obstructive lung diseases: airway inflammation and heightened responsiveness $(1$, $6,7)$. Despite the potential importance of aspiration in the pathogenesis of acute and chronic inflammatory lung disorders, only recently have animal models been used for the study of the basic mechanisms involved in aspiration-induced airway dysfunction (8).

Early work by Olson et al. (17) revealed that rabbit lungs develop consolidative and interstitial pneumonia with neutrophilic and mononuclear infiltration following the endotracheal instillation of milk. Furthermore, rabbits appear to develop functional alterations characterized by a widened alveolar-toarterial oxygen gradient and decreased compliance (18). Our laboratory has recently investigated the effects of repeated milk aspiration on the airway's neural control in rabbits in vitro (8). These studies showed recurrent aspiration of milk produced significant alterations of the autonomic regulation of the airways leading to an imbalance between the contractile and relaxant responses of the airway smooth muscle (8). Of interest, these changes of airway function appear to reproduce alterations of neural control mechanisms produced by other common environmental stimuli such as allergens and respiratory pathogens $(9-11,19)$.

In this study, we describe alterations of respiratory system mechanics in a murine model of milk aspiration in vivo. After repeated aspiration of milk, we found increased baseline respiratory resistance and enhanced airway responses to Mch, suggesting that changes in the regulation of ASM tone and responsiveness may occur as a result of airway exposure to milk. In addition, we found repeated aspiration of milk is capable of producing a significant recruitment of eosinophils within BAL fluid and lung tissue. The latter finding is of particular importance due to the frequent association between eosinophilia and AHR in the mouse model (20-23). Taken together, our findings suggest that aspiration of milk produces functional and
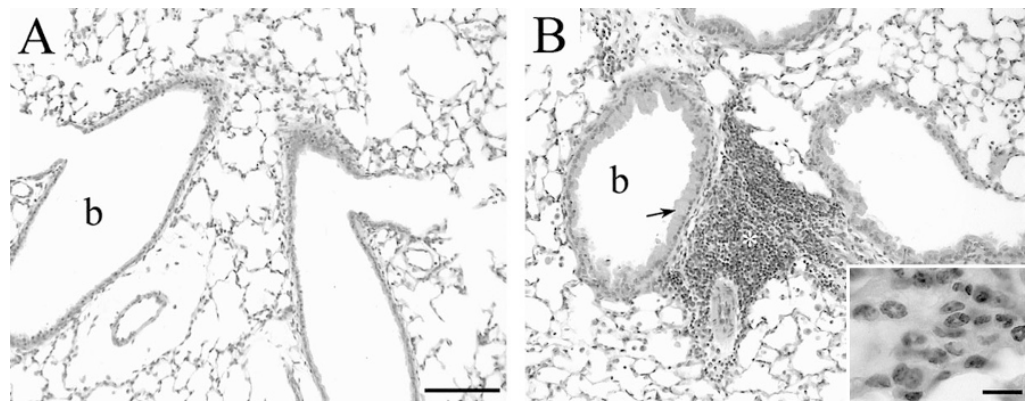

Figure 5. Lung histopathology. Lung sections obtained from control animals $(A)$ and mice exposed to repeated episodes of milk aspiration $(B)$. $(A)$ Representative section revealing normal parenchymal architecture. $(B)$ Representative field of the inflammatory changes produced by milk aspiration characterized by a thickened epithelium (arrow) and diffuse infiltration of mononuclear cells in the peribronchial and interstitial spaces. The area of higher magnification reveals the presence of eosinophils and mononuclear cells within areas of inflammation. Scale bar in $A=100 \mu \mathrm{m}$. Scale bar in $B=10 \mu \mathrm{m}$. 


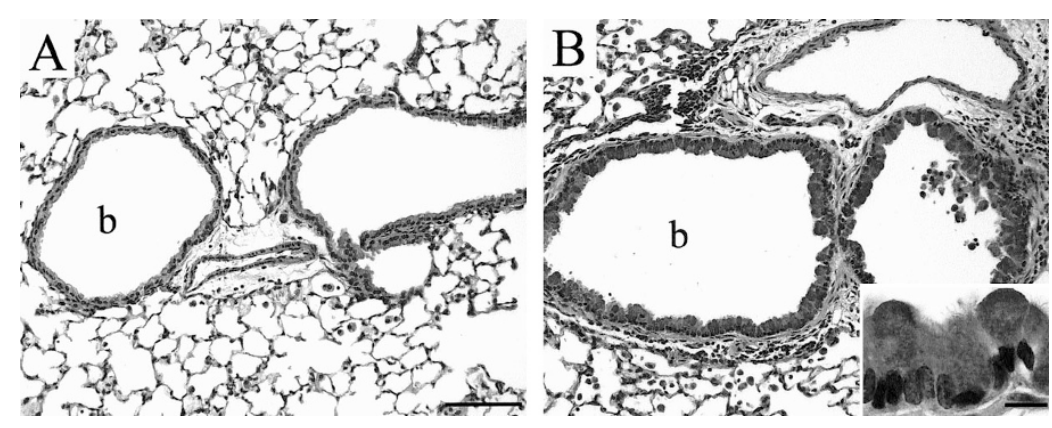

Figure 6. PAS staining of lung sections obtained from control animals $(A)$ and mice exposed to repeated episodes of milk aspiration $(B)$. $(A)$ Representative section of a control animal. $(B)$ Representative field of the changes produced by repeated milk aspiration. The airway epithelium was thickened as a result of marked goblet cell hyperplasia in the airways. The area of higher magnification shows distinct positive staining of goblet cells. Scale bar in $A=100 \mu \mathrm{m}$. Scale bar in $B=10 \mu \mathrm{m}$.

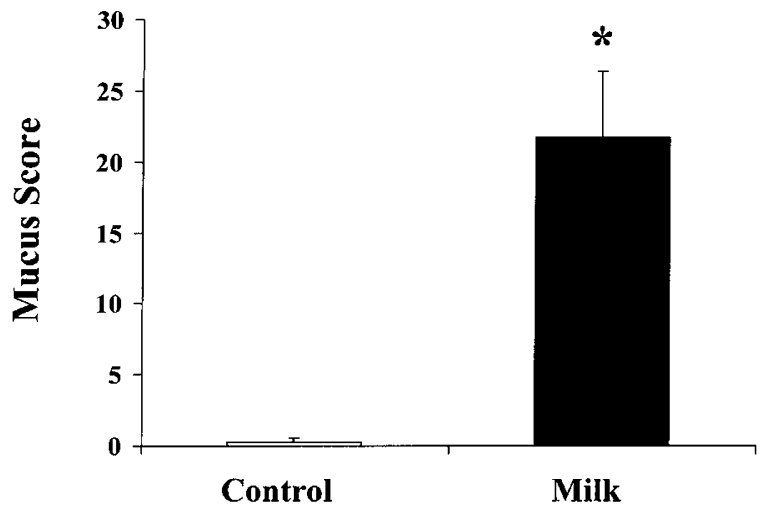

Figure 7. Effect of milk aspiration on mucus index. PAS-stained material was identified on digitized images using Image-Pro® Plus analysis software, and the pixel intensities of each color channel were averaged. This was repeated for each image, and the values averaged to determine the area (M) and intensity (I) of PAS-stained material within the airway walls. In addition, the area (A) of the total epithelium including PAS-staining material was obtained. Results were expressed as mean \pm SE by using a mucus index determined by the following equation: $\mathrm{M} \times \mathrm{I} / \mathrm{A}$. The mucus score was increased by aspiration of milk when compared with control animals $(* p<0.05)$.

cellular changes that mimic asthma-like airway dysfunction in our murine model.

The mouse model of airway dysfunction has become an important mammalian model for the study of the basic mechanisms of asthma and has broadened our knowledge of the immunopathogenesis of airway inflammation and hyperresponsiveness (20-23). Although complex interactions between various inflammatory and immune cells are involved in the asthma-like phenotype seen in the allergen-driven model, there is general agreement that the development of altered airway function is dependent on CD4+ T-lymphocytes and that eosinophils are the effectors of this response $(20-23)$. In this respect, recent studies have further defined the cell signaling involved in the recruitment and activation of eosinophils within the lung, the development of an IgE immune state, and their association with AHR (20-24). Several cytokines appear to play a critical role in the pathologic and functional changes seen in mammalian models of asthma (22). Interleukin (IL)-5, IL-3, IL-13, and granulocyte-macrophage colony-stimulating factor are involved in the recruitment and activation of eosinophils (22-25). IL-4 is involved in the isotype switching in B cells from IgG2a and $2 b$ to produce $\operatorname{IgG} 1$ (in mice) and $\operatorname{IgE}$ (a hallmark of atopy in human asthma) $(22,26)$. In addition, IL-4 is involved in activation of mast cells thus leading to the release of several proinflammatory cytokines and chemotactic factors that could contribute to the altered airway function (22, $27,28)$. Using knockout mice and cytokine antagonists, it has become evident that a cytokine imbalance with predominance of Th2 cells is capable of producing an environment favorable for the development of eosinophilic inflammation, increased IgE, and AHR (22).

In light of these observations, it is possible to speculate that repeated aspiration of milk may lead to a Th2-type microenvironment, similar to the allergen-driven cytokine imbalance produced in the mouse model, with subsequent development of an IgE immune state and lung eosinophilia. These changes would not be surprising due to clinical and laboratory observations on the ability of milk aspiration to induce allergic sensitization. Boulloche et al. demonstrated that infants with milk aspiration had increased total serum IgE and specific IgE to cow's milk compared with control infants and children with sudden infant death syndrome (29). In both children and rabbits, the serum concentration of specific $\operatorname{IgG}$, IgA, and $\operatorname{IgE}$ antibodies to BSA, $\alpha$-lactalbumin, $\beta$-lactoglobulin, $\alpha$-casein, and gammaglobulin are higher after recurrent milk aspiration when compared with control values (30). Furthermore, several reports of IgE-mediated hypersensitivity associated with significant respiratory symptoms have been described following exposure to milk proteins (31-33).

A direct relationship between eosinophilic inflammation and AHR has not been invariably observed $(22,34)$. Therefore, additional mechanisms other than eosinophilic inflammation and cytokine imbalance could be involved in the development of AHR in our murine model. The role of the airway epithelium in respiratory pathophysiology is increasingly recognized (35-37). The epithelial lining of the airways is capable of modulating several cellular responses within the lung, including airway smooth muscle tone and responsiveness (35-37). Several changes in the metabolic function of the airway epithelium are capable of disrupting the airway control. Loss of NEP and release of bronchoconstrictor agents have been well described in conditions associated with airway inflammation and hyperresponsiveness $(38,39)$. Furthermore, the phenotypical changes involving the airway epithelium after milk aspiration are strikingly similar to the alterations described in 
allergen-driven (40) and IgE-mediated milk hypersensitivity murine models of lung inflammation (41). Although further work is needed to evaluate the effects of milk aspiration on epithelial cell function, it is possible that loss of NEP may enhance the physiologic effects of bioactive peptides due to decreased enzymatic inactivation $(38,39)$. In addition, a thickened airway epithelium and goblet cell hyperplasia with enhanced mucus production, as shown in our murine model, may contribute to increased airway tone and responsiveness (40).

In summary, we have developed a murine model in an attempt to characterize the effects of milk aspiration on airway mechanics. In addition, we evaluated whether aspiration of milk produces inflammatory changes within the lung. Our results demonstrate that repeated milk aspiration produces AHR, eosinophilic inflammation, and goblet cell hyperplasia. Due to the striking resemblance of these changes with human and experimental asthma, our model could represent an unprecedented tool for the study of the cell signaling involved in aspiration-induced airway dysfunction. Of particular interest is the fact that airway hyperresponsiveness and inflammation are produced by a stimulus (milk) that is believed to be an important cause of wheezing in young children and a potential risk factor for the development of asthma $(4,33)$. Further studies are needed to define the cell signaling involved in the development of airway dysfunction, eosinophilia, and mucus production in response to milk aspiration.

\section{REFERENCES}

1. Colombo JL 1993 Pulmonary aspiration. In: Hilman BC (ed) Pediatric Respiratory Disease: Diagnosis and Treatment. WB Saunders, Philadelphia, pp 429-436

2. Bauer ML, Rigueroa-Colon R, Georgeson K, Young DW 1993 Chronic pulmonary aspiration in children. S Med J 86:789-795

3. Fan LL 1998 Pediatric interstitial lung disease. In: Schwartz MI, King TE (eds) Interstitial Lung Disease. BC Decker Inc., Hamilton, ON, Canada, pp 103-118

4. Orenstein SR, Orenstein DM 1988 Gastroesophageal reflux and respiratory disease in children. J Pediatr 112:847-858

5. Fan LL, Lum Lung MC, Wagener JS 1997 The diagnostic value of bronchoalveolar lavage in immuno-competent children with chronic diffuse pulmonary infiltrates. Pediatr Pulmonol 23:8-13

6. Sheikh S, Goldsmith LJ, Howell L, Hamlyn J, Eid N 1999 Lung function in infant with wheezing and gastroesophageal reflux. Pediatr Pulmonol 27:236-241

7. Sheikh S, Stephen T, Howell L, Eid N 1999 Gastroesophageal reflux in infants with wheezing. Pediatr Pulmonol 28:181-186

8. Gelfand AS, Larsen GL, Loader JE, Fan LL, Colasurdo GN 1997 Effects of recurrent milk aspiration on neural control mechanisms in rabbit airways in vitro. Pediatr Pulmonol 23:198-204

9. Colasurdo GN, Loader JE, Graves JP, Larsen GL 1995 Maturation of the nonadrenergic noncholinergic inhibitory system in normal and allergen-sensitized rabbits. Am J Physiol 267:L739-L744

10. Colasurdo GN, Hemming VG, Prince GA, Gelfand AS, Loader JE, Larsen GL 1998 Human respiratory syncytial virus produces prolonged alterations of neural control in airways of developing ferrets. Am J Respir Crit Care Med 157:1506-1511

11. Colasurdo GN, Hemming VG, Prince GA, Loader JE, Graves JP, Larsen GL 1995 Human respiratory syncytial virus affects nonadrenergic noncholinergic inhibition in cotton rat airways. Am J Physiol 268:L1006-1011

12. Elidemir O, Fan LL, Colasurdo GN 2000 A novel diagnostic method for pulmonary aspiration in a murine model: immunocytochemical staining of milk proteins in alveolar macrophages. Am J Respir Crit Care Med 161:622-626
13. Shardonofsky FR, Venzor J, Barrios R, Leong KP, Huston DP 1999 Therapeutic efficacy of an anti-IL-5 monoclonal antibody delivered into the respiratory tract in a murine model of asthma. J Allergy Clin Immunol 104:215-221

14. Bates JHT 1989 Correcting for the thermodynamic characteristics of a body plethysmograph. Ann Biomed Eng 17:647-655

15. Shardonofsky FR, Sato J, Bates JHT 1990 Quasi-static pressure-volume hysteresis in the canine respiratory system. J Appl Physiol 68:2230-2236

16. Lauzon AM, Bates JHT 1991 Estimation of time-varying respiratory mechanical parameters by recursive least squares. J Appl Physiol 71:1159-1165

17. Olson M 1970 The benign effects on rabbits' lungs of the aspiration of water compared to $5 \%$ glucose or milk. Pediatrics 46:538-547

18. O'Hare B, Lerman J, Endo J, Cutz E 1996 Acute lung injury after instillation of human breast milk or infant formula into rabbits' lungs. Anesthesiology 84:386-391

19. Larsen GL, Colasurdo GN 1999 Neural control mechanisms with airways: disruption by respiratory syncytial virus. J Pediatr 135:S21-27

20. Larsen GL, Colasurdo GN 1997 Animal models of asthma. In: Crystal RG, West JB, Weibel ER, Barnes PJ (eds) The Lung Scientific Foundation, 2nd Ed. Raven Press, New York, pp 1315-1331

21. Abraham WM, Baugh LE 1995 Animal models of asthma. In: Busse WW, Holgate ST (eds) Asthma and Rhinitis. Blackwell Scientific Publications, Inc., Boston, pp 961-977

22. Pauwels RA, Brusselle GJ, Kips JC 1997 Cytokine manipulation in animal models of asthma. Am J Respir Crit Care Med 156:S78-S81

23. Robinson DS, Hamid Q, Ying S, Tsicopoulos A, Barkans I, Bentley AM, Corrigan C, Durham SR 1992 Predominant TH-2like bronchoalveolar T-lymphocyte population in atopic asthma. N Engl J Med 326:298-304

24. Barnes PJ 1996 Pathophysiology of asthma. Br J Clin Pharmacol 42:3-10

25. Venge J, Lampinen M, Hakansson L, Rak S, Venge 1996 Identification of IL-5 and RANTES as the major eosinophil chemoattractants in the asthmatic lungs. J Allergy Clin Immunol 97:1110-1115

26. Finkelman FD, Katona IM, Urban JF, Holmes J, Ohara J 1988 IL-4 is required to generate and sustain in vivo IgE responses. J Immunol 141:2335-2341

27. Hamaguchi Y, Kanakura Y, Fujita I, Takeda S, Nakano T, Tarui S, Honjo T, Kitamura Y 1987 Interleukin 4 as an essential factor for in vitro clonal growth of murine connective tissue-type mast cells. J Exp Med 165:268-273

28. Gordon JR, Burd PR, Galli SJ 1990 Mast cells as a source of multifunctional cytokines. Immunol Today 11:458-464

29. Boulloche J, Mallet E, Basuyau JP, Tayot P, Samson-Dollfus D 1986 The value of serum IgE assay in milk aspiration and the sudden infant death syndrome. Acta Paediatr Scand 75:530-533

30. Muller W, Buhling T 1988 Systemic humoral immune responses to dietary proteins after oral and inhalation immunization. Monatsschr Kinderheilkd 136:38-43

31. Vargiu A, Vargiu G, Locci F, Del Giacco S, Del Giacco GS 1994 Hypersensitivity reactions from inhalation of milk proteins. Allergy 49:386-387

32. Bernaola G, Echechipia S, Urrutia I, Fernandez E, Audicana M, Fernandez deCorres L 1994 Occupational asthma and rhinoconjunctivitis from inhalation of dried cow's milk caused by sensitization to $\alpha$-lactalbumin. Allergy 49:189-191

33. Businco L, Falconeiri P, Giampietro P, Bellioni B 1995 Food allergy and asthma. Pediatr Pulmonol 11(suppl):59-60

34. Wilder JA, Collie DDS, Wilson BS, Bice DE, Lyons CR, Lipscomb MF 1999 Dissociation of airway hyperresponsiveness from immunoglobulin $\mathrm{E}$ and airway eosinophilia in a murine model of allergic asthma. Am J Respir Cell Mol Biol 20:1326-1334

35. Laitinen LA, Heino M, Laitinen A, Kava T, Haahtela T 1985 Damage of the airway epithelium and bronchial reactivity in patients with asthma. Am Rev Respir Dis 131:599-606

36. Laitinen A, Laitinen LA 1992 Structural changes and cell findings in airway epithelium in asthmatic patients. Res Clin Forums 14:59-64

37. Robbins RA, Rennard SI 1997 Biology of airway epithelial cells. In: Crystal RG, West JB, Weibel ER, Barnes PJ (eds) The Lung Scientific Foundation. LippincottRaven Publishers, Philadelphia, pp 445-457

38. Dusser DJ, Jacoby DB, Djokic TD, Rubinstein I, Borson DB, Nadel JA 1989 Virus induces airway hyperresponsiveness to tackykinins: role of neutral endopeptidase. J Appl Physiol 67:1504-1511

39. Borson DB 1991 Roles of neutral endopeptidases in airways. Am J Physiol 260(suppl 4):L212-L225

40. Blyth DI, Pedrick MS, Savage TJ, Hessel EM, Fattah D 1996 Lung inflammation and epithelial changes in a murine model of atopic asthma. Am J Respir Cell Mol Biol $14: 425-438$

41. Li X, Schofield BH, Huang CK, Kleiner GI, Sampson HA 1999 A murine model of IgE-mediated cow's milk hypersensitivity. J Allergy Clin Immunol 103(2):206-214 